\title{
BMJ Open Impacts of social support on the treatment outcomes of drug-resistant tuberculosis: a systematic review and meta-analysis
}

\author{
Shuqin Wen (D) ,1,2 Jia Yin, ${ }^{1,2}$ Qiang Sun ${ }^{1,2}$
}

To cite: Wen S, Yin J, Sun Q. Impacts of social support on the treatment outcomes of drug-resistant tuberculosis: a systematic review and meta-analysis. BMJ Open 2020;10:e036985. doi:10.1136/ bmjopen-2020-036985

- Prepublication history for this paper is available online. To view these files, please visit the journal online (http://dx.doi. org/10.1136/bmjopen-2020036985).

Received 14 January 2020 Revised 25 August 2020 Accepted 03 September 2020

Check for updates

(c) Author(s) (or their employer(s)) 2020. Re-use permitted under CC BY-NC. No commercial re-use. See rights and permissions. Published by BMJ.

${ }^{1}$ Centre for Health Management and Policy Research, School of Public Health, Shandong University Cheeloo College of Medicine, Jinan, Shandong, China

${ }^{2} \mathrm{NHC}$ Key Lab of Health Economics and Policy Research, Shandong University, Jinan, Shandong, China

Correspondence to Jia Yin; yinjia@sdu.edu.cn

\section{ABSTRACT}

Objective To assess the effectiveness of social support on treatment success promotion or lost to follow-up (LTFU) reduction for patients with drugresistant tuberculosis (DR-TB).

Design We searched Pubmed, Web of Science, Embase, Scopus and Medline databases until 18 June 2020 for interventional or mixed-method studies which reported social support and treatment outcomes of DR-TB patients. Two independent reviewers extracted data and disagreements were resolved by consensus with a third reviewer. Random-effects meta-analysis was performed to calculate the $\mathrm{OR}$ and $95 \% \mathrm{Cl}$ for the effects of social support on the improvement of treatment outcomes and the heterogeneity and risk of bias were assessed.

Setting Low-income and middle-income countries. Participants DR-TB patients.

Outcomes Treatment success is defined as the combination of the cured and treatment completion, and LTFU is measured as treatment being interrupted for two consecutive months or more.

Results Among 173 articles selected for full-text review, 162 were excluded through independent review (kappa=0.87) and 10 studies enrolling 1621 DR-TB patients in eight countries were included for qualitative analysis. In these studies, the most frequently introduced social support was material support (10 studies), followed by informational (eight studies), emotional (seven studies) and companionship support (four studies). Seven studies that reported treatment outcomes in both intervention arm and control arm are qualified for meta-analysis. An encouraging improvement on treatment success rate (OR: 2.58; 95\% Cl: 1.80 to 3.69) was found when material support was integrated into social support packages and no heterogeneity was observed ( $I^{1}$ of $0 \%, Q$ test $p=0.72$ ). Reduction on LTFU rate (OR: 0.17 ; $95 \% \mathrm{Cl}: 0.05$ to 0.55$)$ was also noted when material support was available but substantial heterogeneity was found ( $P^{2}$ of $80 \%, Q$ test $\left.p=0.002\right)$.

Conclusion Material support appeared feasible and effective to improve treatment success for DR-TB patients combined with other social support interventions.

PROSPERO registration number CRD42019140824.
Strengths and limitations of this study

- It is the first systematic review and meta-analysis revealing the positive effects of integrated social support directly on the final treatment outcomes for drug-resistant tuberculosis (DR-TB) patients.

- Social support interventions are categorised and fully described in this study, providing reasonable strategies for their further integration into DR-TB control framework.

- The major concern is lacking of studies which did not apply material support in meta-analysis.

- The variation in participants' characteristics and social support and limited quantity of relevant literature were also considered as limitations.

\section{INTRODUCTION}

The epidemic of drug-resistant tuberculosis (DR-TB) remains a major public health threat in many countries, and it has been one of the main obstacles in the success of achieving 2030 targets set in the End TB Strategy. Globally, DR-TB commonly contains three types of resistance, which are rifampicin resistance (RR-TB, resistance to rifampicin with or without resistance to other anti-TB drugs), multidrug resistance (MDR-TB, resistance to at least both isoniazid and rifampicin) and extensive drug resistance (XDR-TB, resistance to any fluoroquinolone and at least one of three second-line injectable drugs, in addition to MDR-TB). ${ }^{1}$ Between 2016 and 2017, the number of reported MDR-TB and RR-TB cases increased by more than $30 \%$ in six of the 30 high MDR-TB burden countries. ${ }^{2}$ Some studies suggested that recently transmission of MDR-strain and XDR-strain has become the dominant spread pattern, rather than the emergence of drug resistance caused by inappropriate antibiotic 
use, ${ }^{34}$ which highlighted the importance of DR-TB prevention and control. As agreed by researchers from different countries, ${ }^{56}$ controlling the epidemic of DR-TB plays a vitally significant role in global TB control and public health.

WHO has published guidelines of National Tuberculosis Control Programme (NTP) to promote the management of TB and DR-TB and it has been widely applied to many countries. ${ }^{7-11}$ Four-level (central, regional, district and peripheral) organisation structure is suggested to support the implementation of Directly Observed Therapy (DOT), diagnosis and treatment network. ${ }^{9}$ However, the total number of MDR-TB patients, still rose by approximately $20 \%$ annually from 2009 to $2017^{112}$ and the effects of DOT were also unsatisfactory to some extent. ${ }^{13}{ }^{14}$ Control of DR-TB still encounters many intricate challenges. First, psychosocial challenges that DR-TB patients face, for example, stigma and psychological distress, have been reported widely, and cause poor adherence and treatment outcomes. ${ }^{15-17}$ Thus, patients with MDR-TB revealed a strong appeal of social support. ${ }^{18} 19$ Unlike physical interventions, psychosocial environment could affect the effectiveness of behavioural interventions. ${ }^{4}$ Second, the median cost for MDR-TB was US\$7141 in 2017, which was almost six times higher than drug-susceptible TB. ${ }^{2}$ The direct and indirect costs for DR-TB treatment are unaffordable for many patients, but social protection has been proven to be effective to alleviate catastrophic expenses outpatient-based care with social support (such as food packages and transport vouchers) is more affordable and cost-effective than hospitalisation. ${ }^{20-22}$ Although social support seems feasible to be integrated into NTP, the effectiveness of social support on the improvement of DR-TB treatment outcomes was rarely reported.

A systematic review done by Thomas discussed the neurological side-effects (depression, convulsion and psychosis), emotional insecurity, stigma and reshaped psychological state, but the effects of social support interventions were unclear. $^{15}$ Social support was mentioned as a part of effective strategies to reduce treatment default by Toczek and Weaver, ${ }^{23}{ }^{24}$ while relevant information about the implementation of strategies, such as the duration, content and provider, were poorly documented. A review advanced by van Hoorn revealed the effects of psycho-emotional and socialeconomic support, but the research focused on drugsusceptible TB patients, instead of DR-TB patients who suffer from longer medication period, more expensive medication and severer side-effects. ${ }^{25}$ In this systematic review, we sought to identify the effects of social support on DR-TB patients. We explored the direct impact of social support on final treatment outcomes, rather than on indirect treatment adherence or selfreported benefits, defined social support based strictly on the WHO DR-TB guideline, ${ }^{26}$ and revealed how these social support interventions are implemented in detail.

\section{METHODS}

\section{Study design and search strategies}

We conducted a systematic review and meta-analysis to summarise interventional studies. This systematic review was arranged in accordance with the Cochrane Handbook for Systematic Reviews and the Preferred Reporting Items for Systematic Reviews and MetaAnalysis guidelines. ${ }^{27} 28$

We searched PubMed, Web of Science, Medline, Embase and Scopus to identify relevant articles published before 19 June 2020. The combination of DR-TB (drug-resistant tuberculosis, multidrugresistant tuberculosis, rifampicin-resistant tuberculosis, DR-TB, MDR-TB, RR-TB and so on) and social support (informational, emotional, companionship and material support) was used as search term. Information support includes health education, counselling, DR-TB brochures and so on; emotional support includes all kinds of psychological interventions and encouragement; material support refers to different kinds of sources to deal with patients' financial burden (eg, travel reimbursement, free treatment and nutrition provision) and companionship support could be the help for patients to participate in a social network (eg, peer counselling). Then, we added other relevant studies from systematic reviews of social support for DR-TB patients. ${ }^{15242529}$

\section{Definitions of social support and treatment outcomes}

We identified social support by a commonly used framework advanced by the $\mathrm{WHO},{ }^{26}$ which includes four distinct subtypes: (1) informational support: including training, education and counselling; (2) emotional support: refers to all expressions of care that strengthen self-esteem through empathy, trust, encouragement and care; (3) companionship support: defined as the help that makes a person feel that he or she belongs to the social network, and that he or she can rely on it for certain needs and (4) material support: all commodities, including financial subsidies.

According to WHO guidelines, treatment outcomes for RR-TB/MDR-TB/XDR-TB consist of cured, treatment completed, treatment failed, died, lost to follow-up (LTFU), not evaluated and treatment success. ${ }^{1}$ Treatment success is the combination of cured and treatment completed. 'Cured' refers to treatment completed without evidence of failure and three or more consecutive cultures taken at least 30 days apart showing negative after the intensive phase, while 'treatment completion' means treatment completed without evidence of failure but no record that three or more consecutive cultures taken at least 30 days apart are negative after the intensive phase. 'LTFU' indicates that the treatment was interrupted for 
Table 1 Risk of bias assessment on social support interventions to improve DR-TB treatment outcomes

\begin{tabular}{|c|c|c|c|c|c|c|c|}
\hline Study & $\begin{array}{l}\text { Selection } \\
\text { bias }\end{array}$ & Design & Confounders & Blinding & $\begin{array}{l}\text { Data } \\
\text { collection } \\
\text { method }\end{array}$ & $\begin{array}{l}\text { Withdrawals } \\
\text { and dropouts }\end{array}$ & $\begin{array}{l}\text { Global } \\
\text { rating }\end{array}$ \\
\hline Li et $a l^{11}$ & Strong & Moderate & Strong & Moderate & Moderate & Strong & Moderate \\
\hline Yin et $a l^{19}$ & Moderate & Moderate & Strong & Moderate & Moderate & Moderate & Moderate \\
\hline Luyirika et $a{ }^{38}$ & Moderate & Weak & Weak & Weak & Moderate & Strong & Weak \\
\hline Oyieng'o et $\left.a\right|^{39}$ & Moderate & Moderate & Weak & Moderate & Strong & Strong & Moderate \\
\hline Baral et $a l^{41}$ & Moderate & Moderate & Strong & Moderate & Moderate & Strong & Moderate \\
\hline Brust et $a l^{42}$ & Strong & Moderate & Weak & Moderate & Moderate & Strong & Moderate \\
\hline Acha et $a l^{43}$ & Strong & Moderate & Weak & Moderate & Moderate & Strong & Moderate \\
\hline Mohr et $a l^{44}$ & Moderate & Moderate & Strong & Weak & Moderate & Strong & Moderate \\
\hline
\end{tabular}

DR-TB, drug-resistant tuberculosis.

two consecutive months or more. In this review, treatment success and LTFU were invoked as indicators of treatment outcomes as they were most frequently reported.

\section{Inclusion criteria}

Studies were included if they met all the following criteria. (1) Study designs: interventional (randomised or non-randomised controlled trials (RCTs), quasiexperiment, before-and-after studies, prospective and retrospective cohorts) or mixed-method studies. (2) Categories of participants: DR-TB (RR-TB, MDR-TB or XDR-TB) patients were identified if they met any of the following three standards: culture-confirmed DR-TB with at least first-line drug susceptibility testing; or patients registered in DR-TB programmes or centres which meant they had previously been diagnosed; or patients were adopting DR-TB medication regimens. (3) Interventions: in addition to the supports from NTP, any one or more of the four types of social support (informational, emotional, companionship and material) were provided to patients. (4) Comparison: studies with comparison group were included for meta-analysis if patients in control arm were not provided with any type of social support other than supports from NTP (only included for meta-analysis). (5) Treatment outcomes: treatment success or LTFU.

\section{Exclusion criteria}

The following studies were excluded. (1) Studies only reporting DOT as social support intervention were excluded because it was not the priority of our interest and had been previously studied by other researchers. $^{3031}$ (2) Studies only conducted in short intensive phase were excluded because during hospitalisation (intensive phase), the support from physicians and nurses may confound the impacts of social support, and treatment success or LTFU of DR-TB normally could not be observed in short intensive phase. (3) When the intervention duration was less than 6 months, studies were excluded to avoid bias towards final treatment outcomes. (4) Studies conducted in the same location during the same period were considered as potential duplicates and it was verified by contacting authors for clarification.

\section{Data extraction}

Two reviewers conducted the literature searching independently and subsequently consolidated studies together. Then they screened the titles and abstracts to extract data. For the controversial studies, the research members discussed with the third independent reviewer to reach an agreement. Endnote X8 was used to cite and manage all the data. In addition, extracted studies were recorded by a predesigned extracting Microsoft Excel form to collect information of country, duration, location, methods, number of participants, DOT involved, interventions and outcomes, and verified by a second reviewer. When study findings were uncertain or missing, we contacted the authors for details.

\section{Methodological quality assessment}

Due to the lack of RCTs, we used the Effective Public Health Practice Project, ${ }^{32} 33$ instead of the Cochrane Collaboration's Tool, to independently assess the risk of bias, based on selection bias (the representative of target population), design (study design), confounders (control of confounders), blinding (blinding of outcome assessors and participants), data collection methods (the validity and reliability of data collection tools), withdrawals and dropouts (follow-up rate). Specifically, global rating was assessed based on the principle that strong evidence refers to those with no weak ratings and at least four strong ratings, 


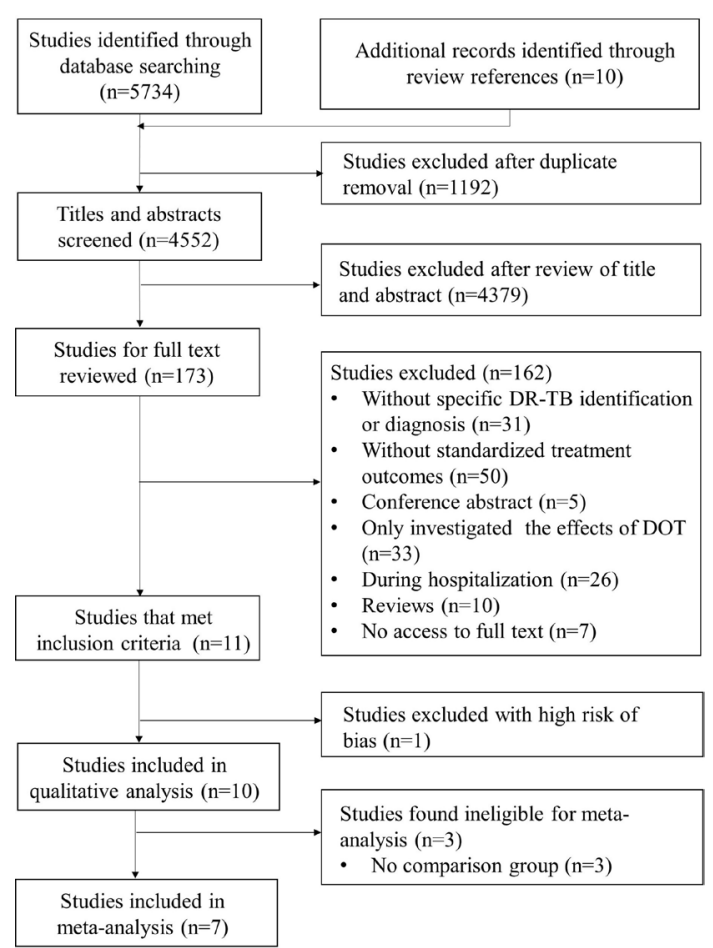

Figure 1 Flowchart showing the selection of studies on social support interventions to improve DR-TB treatment outcomes. DOT, Directly Observed Therapy; DR-TB, drugresistant tuberculosis.

moderate evidence refers to those with less than four strong ratings and one weak rating and those with two or more weak ratings are considered weak.

\section{Statistical analysis}

We introduced a narrative synthesis to demonstrate the characteristics of all included studies. For seven studies that set comparison groups, meta-analysis was applied to describe the impacts of social support by forest plots. Mantel-Haenszel model and random-effects method were used to obtain the ORs and $95 \%$ CIs for the unadjusted treatment success rates and LTFU rates. Subgroup analysis was performed to adjust the effects of material support; we assumed material support was essential in social support packages because treatment for MDR-TB or XDR-TB was a catastrophic expenditure, costing up to 25 times as much as for drug-susceptible $\mathrm{TB}^{34} 35$ and many reviews revealed the effectiveness and importance of monetary incentives. ${ }^{23} 3637$

Between-group difference was tested by $Q$ statistics and p-value. A p-value less than 0.05 indicated a significant difference. Heterogeneity across studies under each category was assessed by $I^{2}$ statistic and p-value; an $I^{2}$ was greater than $50 \%$ with $\mathrm{p}<0.05$ indicated the existence of significant heterogeneity across studies. Resources of the heterogeneity, including HIV prevalence, the application of DOT and the classification of DR-TB were not analysed, as there was not sufficient information available to complete a meta-regression model that used any of these variables. Sensitivity analyses were completed by excluding one primary study at a time and assessing the new pooled treatment success rate and LTFU rate. Publication bias was not assessed because only seven studies were available. All meta-analyses were carried out by using Review Manager V.5.3 (Cochrane Collaboration, Copenhagen, Denmark).

\section{Patient and public involvement \\ No patient involved.}

\section{RESULTS}

In total, we identified 5734 studies from e-journal databases, among which 173 records were identified as potentially relevant by abstract screening, and 162 records were excluded through independent full-text review (kappa $=0.87$, high agreement). A total of 11 studies met the inclusion criteria and corresponding researchers were contacted to request clarification if needed. The quality of each study is presented in table 1 and one case study was excluded due to the weak global rating, as there was only one participant and the control of confounders and the blinding were missed. ${ }^{38}$ Therefore, 10 studies with 1621 DR-TB patients were finally included in the analysis. Figure 1 shows the selection process.

\section{Characteristics of the included studies}

Among the 10 studies published between 2007 and 2019, five were conducted in Asia (China, India and Nepal), three in Africa (South Africa and Kenya) and two in South America (Ecuador and Peru). Six studies ${ }^{19-43}$ focused on MDR-TB, one ${ }^{44}$ only involved RR-TB patients, three ${ }^{11}$ 4546 involved all types of DR-TB. ${ }^{42}$ Four studies ${ }^{11} 194246$ clearly gave information about the arrangement of drug susceptibility tests, and three other studies clarified the DR-TB medication intake ${ }^{39434}$ and the rest recruited patients enrolled in TB programmes: NTP in Ecuador, ${ }^{45}$ China, ${ }^{11} \mathrm{Nepal}^{41}$ and Revised NTP in India. ${ }^{40}{ }^{46}$ Seven studies $^{11} 1939{ }^{42-45}$ performed DOT, two studies ${ }^{41}{ }^{46}$ mentioned patients were chosen from DOTS centres but did not illustrate if DOT was provided for full course of treatment and one study ${ }^{40}$ did not apply DOT for the social support group (table 2). Final treatment outcomes of DR-TB patients were shown in table 3 .

\section{Social support interventions}

While eight of the 10 studies implemented integrated social support interventions, ${ }^{199-44} 46$ two other studies only provided single intervention in form of monetary incentives. ${ }^{1145}$ Table 4 shows the details of social support strategies. Among the four subcategories of social support interventions, the most frequently introduced intervention was material support as 10 studies implemented it, followed by informational support (eight studies), emotional support (seven studies) and companionship support (four studies).

Material support included monetary incentives and basic necessities. The monetary incentives was mentioned 


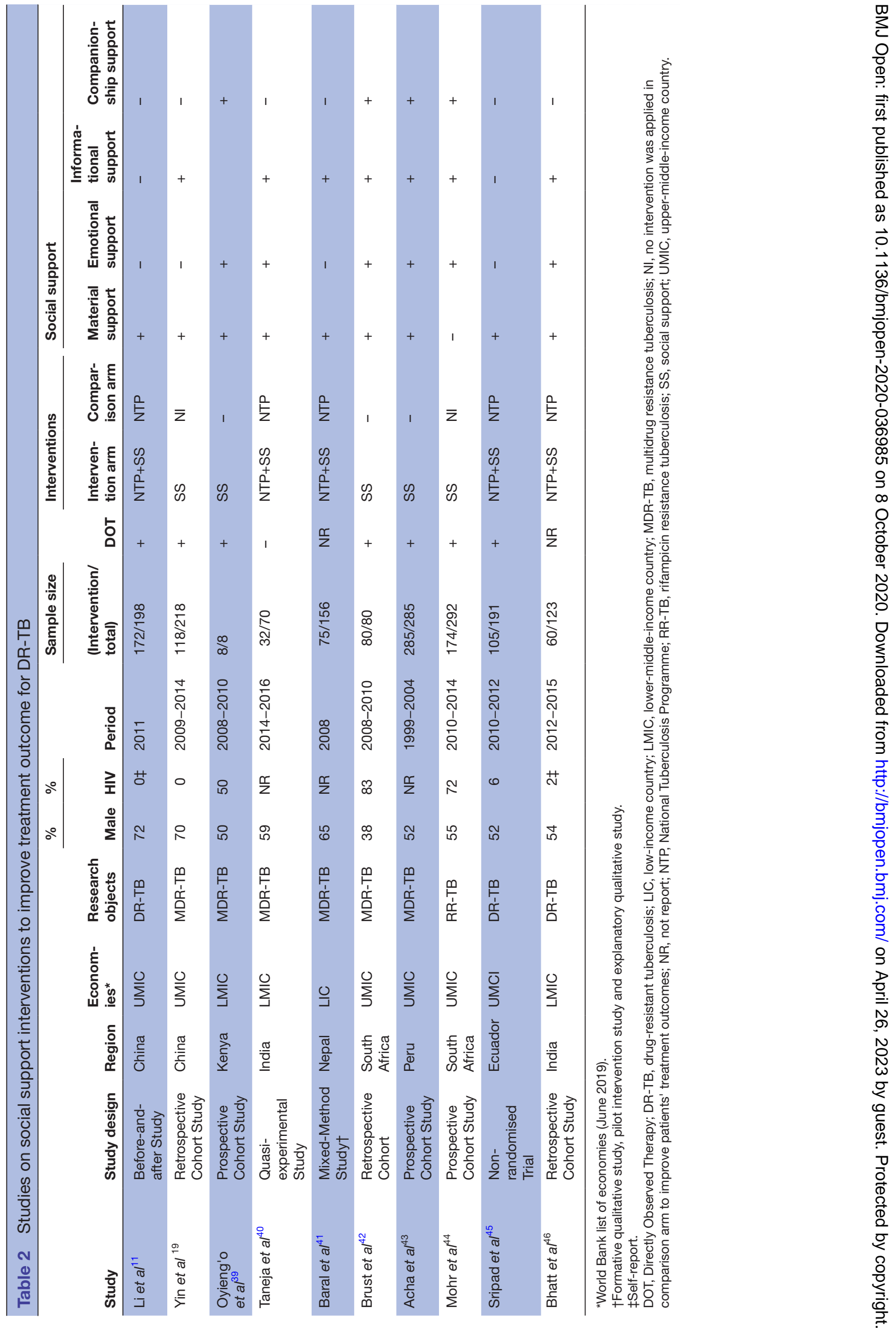


Table 3 Treatment outcomes of DR-TB patients for social support interventions

\begin{tabular}{|c|c|c|c|c|c|c|c|c|}
\hline \multirow[b]{3}{*}{ Study } & \multicolumn{4}{|c|}{ Treatment success } & \multicolumn{4}{|c|}{ Loss to follow-up } \\
\hline & \multicolumn{2}{|c|}{ Intervention arm } & \multicolumn{2}{|c|}{ Comparison arm } & \multicolumn{2}{|c|}{ Intervention group } & \multicolumn{2}{|c|}{ Comparison group } \\
\hline & $\begin{array}{l}\text { Treatment } \\
\text { success }\end{array}$ & $\begin{array}{l}\text { Total } \\
\text { sample }\end{array}$ & $\begin{array}{l}\text { Treatment } \\
\text { success }\end{array}$ & $\begin{array}{l}\text { Total } \\
\text { sample }\end{array}$ & LTFU & $\begin{array}{l}\text { Total } \\
\text { sample }\end{array}$ & LTFU & $\begin{array}{l}\text { Total } \\
\text { sample }\end{array}$ \\
\hline Li et $a l^{11}$ & - & - & - & - & 3 & 172 & 12 & 26 \\
\hline Yin et $a l^{19}$ & 92 & 118 & 52 & 100 & - & - & - & - \\
\hline Baral et al ${ }^{41}$ & 60 & 75 & 54 & 81 & 8 & 75 & 15 & 81 \\
\hline Brust et al ${ }^{42}$ & 59 & 80 & - & - & 4 & 80 & - & - \\
\hline Acha et $a l^{43}$ & 171 & 285 & - & - & 10 & 285 & - & - \\
\hline Mohr et al ${ }^{44}$ & 99 & 174 & 66 & 118 & 31 & 174 & 25 & 118 \\
\hline
\end{tabular}

DR-TB, drug-resistant tuberculosis; LTFU, lost to follow-up.

in nine studies, commonly in form of travel reimbursement $^{11193941424446}$ and nutrition bonus; $;^{3940} 46$ and monetary incentives were mostly supplied on a monthly basis, from US $\$ 15.5^{19}$ to US $\$ 240 .^{45}$ One study offered monthly bonus as a reward to stimulate patients if they took medication at least 26 days per month. ${ }^{45}$ Free treatment ${ }^{45}$ and service packages which covered up to $90 \%$ of the treatment costs were also mentioned to alleviate the heavy financial burden brought by the medication regimen. Food was distributed to DR-TB patients as the main necessities, ${ }^{39} 4046$ for example, eggs, grains, milk and cooking oil.

Informational consultations were held regularly in the clinic or at patients' home to assist patients in coping with the complications or adverse effects of medicine and provide health education. ${ }^{19} 40-4446$ The counsellors could also persuade patients to keep taking medication, ${ }^{19} 4044$ review the issue pillbox ${ }^{44}$ and remind medicine renewal. ${ }^{19}$

Emotional support was divided into home visit and psychological support to fuel patients' medical and psychological needs. It was delivered by trained healthcare workers such as nurses and community healthcare workers $^{3940424446}$ to motivate and inform patients and more importantly, to administer injection, ${ }^{39} 42$ oral medication intake, ${ }^{39} 42$ side effects monitor ${ }^{40} 42$ and physical and social assessment. ${ }^{40} 44$ Psychological support was applied in different methods, such as, mental and vocational rehabilitation, ${ }^{40}$ psychological profile evaluation and supporters group sessions. ${ }^{43}$

Companionship support was commonly provided in the form of support from family treatment supporter or social groups that held various activities to meet patients' social needs and rebuilt patients' confidence to recover. Patients' family members, relatives or friends were arranged to be treatment supporters and supervised the medication intake. ${ }^{394244}$ Group activities, including outdoor exercises (excursions) and indoor celebrations for treatment completion, patients' birthdays and international TB days were organised. ${ }^{43}$

\section{Meta-analysis}

Seven studies with control arm were included in the metaanalysis, enrolling a total of 1248 DR-TB patients. Data from five studies ${ }^{19} 40414446$ were synthesised to conduct meta-analysis regarding treatment success rate (figure 2), and five studies $114144-46$ to conduct LTFU rate metaanalysis (figure 3 ).

We performed stratified analysis according to whether material support was involved or not. An encouraging improvement on treatment success rate (OR: 2.58; $95 \%$ CI: 1.80 to 3.69 ) was found as material support was integrated into social support packages, and no heterogeneity was observed $\left(I^{2}\right.$ of $0 \%, Q$ test $\left.\mathrm{p}=0.72\right)$. Sensitivity analysis for treatment success meta-analysis did not modify the heterogeneity and effect size when studies were dismissed from the analysis one by one. Reduction on LTFU rate (OR: 0.17 ; $95 \%$ CI: 0.05 to 0.55 ) was also noted when material support was available. However, substantial heterogeneity was found $\left(I^{2}\right.$ of $80 \%, Q$ test $\mathrm{p}=0.002$ ); we performed sensitivity analysis and found that omitting one study ${ }^{10}$ would remove heterogeneity $\left(I^{2}\right.$ of $\left.6 \%, \mathrm{p}=0.35\right)$ (data not shown). For patients not receiving material support, there were no significant differences in treatment success rates (OR: 1.04; 95\% CI: 0.65 to 1.67 ) and LTFU rates (OR: $0.81 ; 95 \%$ CI: 0.45 to 1.45) compared with the control group.

\section{DISCUSSION}

The findings of this review are consistent with WHO's suggestions that treatment adherence among TB patients could be influenced by factors at individual, economic, health system and social levels, and that most if not all the factors associated 
Table 4 Types of social support interventions to improve treatment outcome for DR-TB

\begin{tabular}{|c|c|c|c|}
\hline Study & Emotional support & Informational support & Companionship support \\
\hline Li et al ${ }^{11}$ & $\begin{array}{l}\text { Monetary incentives } \\
\text { 1. US } \$ 15.5 \text { cash bonus } \\
\text { for transportation and } \\
\text { nutritional supplements } \\
\text { 2. Out-of-pocket payment } \\
\text { reduction to } 10 \% \text { of } \\
\text { the charge for the } \\
\text { treatment services by } \\
\text { government insurance } \\
\text { funding and project } \\
\text { subsidies }\end{array}$ & & $\begin{array}{l}\text { 1. Community care } \\
\text { workers (CCWs) } \\
\text { identified a treatment } \\
\text { supporter for the } \\
\text { patients }\end{array}$ \\
\hline Yin et $a l^{19}$ & $\begin{array}{l}\text { Commodities } \\
\text { 1. US } \$ 10 \text { transport } \\
\text { reimbursement per } \\
\text { month } \\
\text { 2. US } \$ 10 \text { nutrition } \\
\text { support per month }\end{array}$ & $\begin{array}{l}\text { 1. Reminding medications } \\
\text { renewal } \\
\text { 2. Methods to cope with } \\
\text { adverse events } \\
\text { 3. The importance of } \\
\text { adherence }\end{array}$ & \\
\hline
\end{tabular}

$\begin{array}{ll}\text { Oyieng'o et al }^{39} & \begin{array}{l}\text { Monetary incentives } \\ \text { 1. Transport incentives } \\ \text { Commodities }\end{array} \\ \text { 2. Food supply }\end{array}$

Home visit

1. Nurses gave medication and injection administration at patients' home or the nearest healthcare facility at patients' will

Home visit

1. Providers: trained homecare teams visit patients' home every fortnight in intensive phase and every 45 days during continuation phase

2. Content: physical assessment by body weight, side-effects of medicine and complications; motivating patients to take sputum microscopy

Psychological support

1. Addressing emotional needs

2. Providing mental and vocational rehabilitation-getting readmission to schools or encouraging them to work

$\begin{array}{ll}\text { Baral et al }{ }^{41} & \begin{array}{l}\text { Monetary incentives } \\ \text { 1. US } \$ 28 \text { per month to } \\ \text { cover local transport } \\ \text { food and rental costs }\end{array}\end{array}$

Brust et al ${ }^{42} \quad$ Monetary incentives

1. Travel reimbursement for patients and family members

\section{Home visit}

1. Weekly side effects monitor by nurses or community health workers (CHWs)

2. Intensive phase: daily home visit by a nurse and a driver (injection team)

3. Continuation phase: daily visits by $\mathrm{CHWs}$ for DOTs

\begin{tabular}{|c|c|c|}
\hline Acha et al ${ }^{43}$ & $\begin{array}{l}\text { Monetary incentives } \\
\text { 1. Transportation subsidy }\end{array}$ & $\begin{array}{l}\text { Psychological support } \\
\text { 1. Support group sessions } \\
\text { convened bimonthly with 8-12 } \\
\text { patients, one or two cured } \\
\text { patients and health workers } \\
\text { (psychiatrists, nurses, social } \\
\text { workers and health workers) }\end{array}$ \\
\hline
\end{tabular}

1. Small group counselling led by trained public health nurses every 2-3 weeks

1. Weekly education sessions about MDR-TB and HIV for patients and treatment

1. A household member supervised the evening oral dose

1. Disease information

2. Importance of treatment adherence

3. Health education about coughing etiquettes
1. Family members or friends to be treatment supporters
1. Family workshops to increase the awareness about the disease and treatment
1. Daytime recreational excursions several times a year

2. Symbolic celebrations for patients' birthdays, treatment completion, international TB day and other festivals

Continued 
Table 4 Continued

\begin{tabular}{|c|c|c|c|c|}
\hline Study & Material support & Emotional support & Informational support & Companionship support \\
\hline Mohr et $a l^{44}$ & & $\begin{array}{l}\text { Home visit } \\
\text { 1. Social situation assessment by } \\
\text { CCWs } \\
\text { 2. Adherence barriers } \\
\text { identification by CCWs }\end{array}$ & $\begin{array}{l}\text { 1. A MeÂdecins Sans } \\
\text { Frontières counsellor } \\
\text { reviewed the } \\
\text { medication, issued a } \\
\text { pillbox and addressed } \\
\text { the adherence barriers } \\
\text { in clinic }\end{array}$ & \\
\hline
\end{tabular}

\begin{tabular}{|c|c|c|c|}
\hline Sripad et al ${ }^{45}$ & $\begin{array}{l}\text { Monetary incentives } \\
\text { 1. US } \$ 240 \text { bonus each } \\
\text { month after taking } \\
\text { medications at least } 26 \\
\text { days per month for up } \\
\text { to } 24 \text { months }\end{array}$ & & \\
\hline Bhatt et al ${ }^{46}$ & $\begin{array}{l}\text { Monetary incentives } \\
\text { 1. Cash handouts } \\
\text { 2. Reimbursement of } \\
\text { conveyance } \\
\text { Commodities } \\
\text { 1. Nutritional } \\
\text { supplements: milk, } \\
\text { eggs, grains, pulses, } \\
\text { jaggery, biscuits and } \\
\text { cooking oil }\end{array}$ & 1. Motivation & $\begin{array}{l}\text { 1. Patient-provider group } \\
\text { meetings }\end{array}$ \\
\hline
\end{tabular}

DOTs, Directly Observed Therapy; DR-TB, drug-resistant tuberculosis; MDR-TB, multidrug resistance tuberculosis.

with poor adherence can be addressed by providing social support to patients. ${ }^{26}$ Most studies with social support showed significantly improved treatment success rates and the results were in line with other studies that mentioned the positive impacts of social support or part of its interventions on TB $^{2325364748}$ and DR-TB patients. ${ }^{184}$ It could be reasonable to integrate social support into traditional DOTs scheme as it emphasises giving due consideration to patients' values and needs which embodies the patient-centred care approach proposed by the $\mathrm{WHO},{ }^{29}$ while the unified DOT constraint on patients conflicts with patients' autonomy, dignity and integrity. ${ }^{49}$

As the effectiveness of material support in TB patients was widely reported, ${ }^{21}{ }^{50-53}$ this systematic review found that material incentives could be a critical part of social support for DR-TB patients and material support with other social support was an effective strategy for countries at different levels of economic development. The potential mechanism could be that integrated social support with material stimulations contributed to assisting DR-TB patients to better utilise other social support, and complete other social support better. ${ }^{41}$ Patients would be better motivated if they have access to more sufficient material support because they are mostly the poor people in both impoverished and wealthy countries. Although emotional, informational and companionship support were provided, the performance of self-administered treatment was poorer than standard care when DR-TB patients did not have access to material reimbursement; ${ }^{44}$ perhaps, only when patients' heavy financial burden was alleviated to some extent could other social support have the

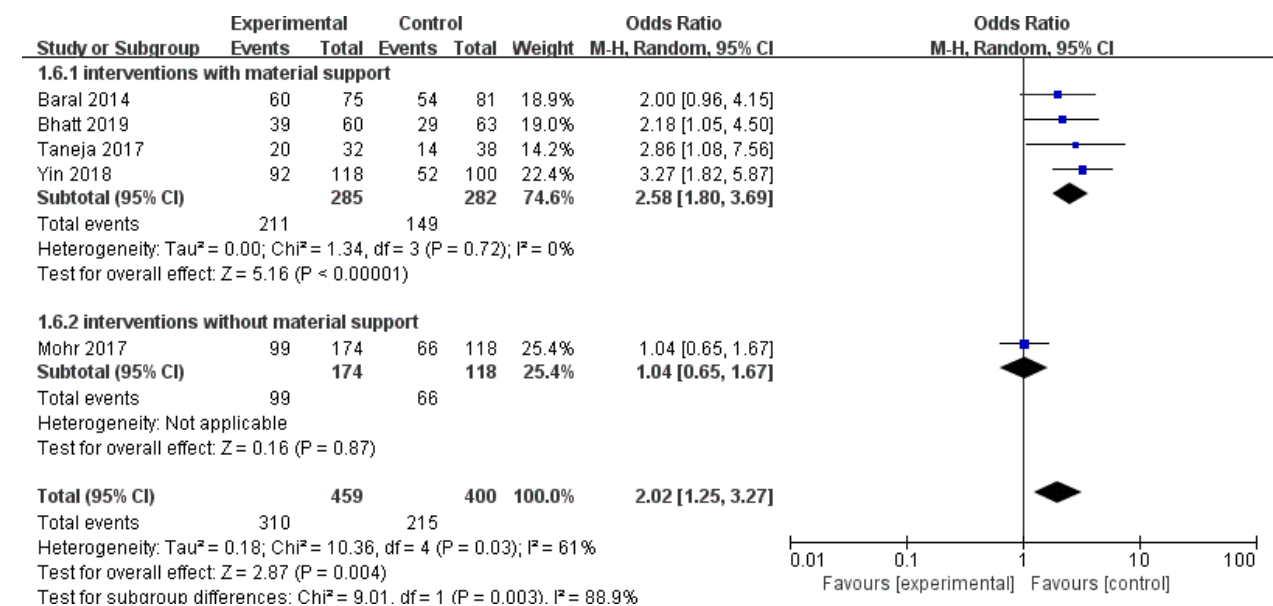

Figure 2 Likelihood of treatment success rate for social support interventions to improve DR-TB clinical outcomes. DR-TB, drug-resistant tuberculosis. 


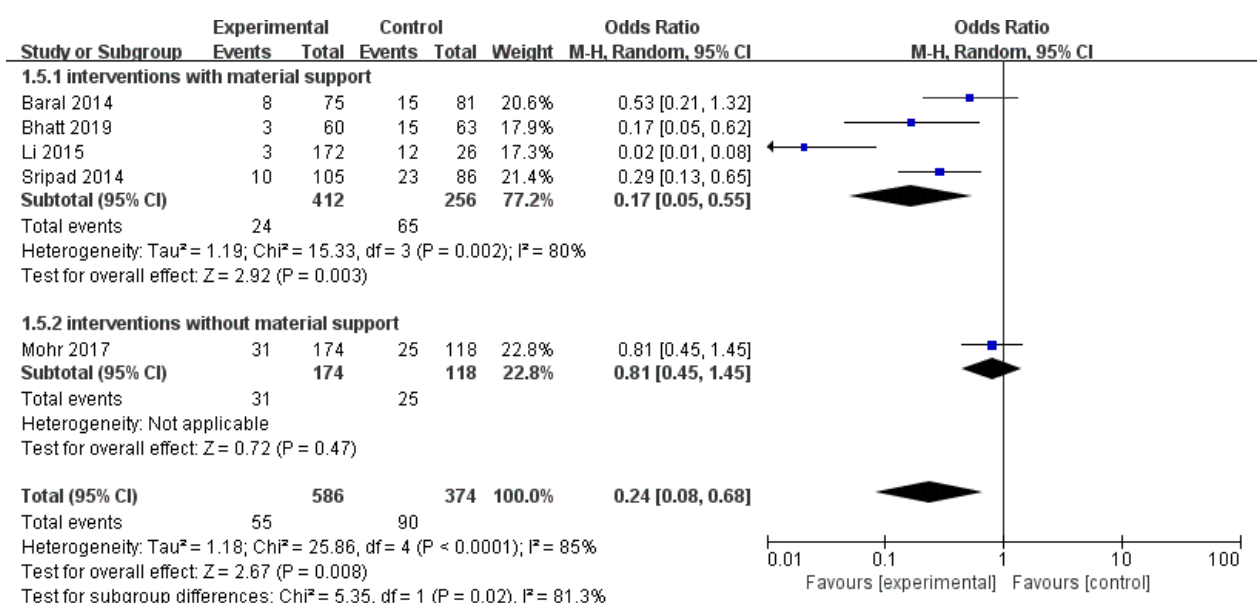

Figure 3 Likelihood of LTFU rate for social support interventions to improve DR-TB clinical outcomes. DR-TB, drug-resistant tuberculosis; LTFU, lost to follow-up.

potential to play their role in promoting patients to complete the treatment. Therefore, if possible, it was suggested that material support be prioritised when social support was arranged. However, caution should be taken when generalising the results, because potential sources of heterogeneity such as the coinfection of HIV were not evaluated.

We noticed that both small ${ }^{19} 4041$ and large amount of subsides ${ }^{1145}$ for DR-TB patients can achieve greater improvement on treatment outcomes when other social supports were provided. Thus, how to utilise limited material support combined with emotional support, psychological support and companionship support and design a cost-effective social support package could be worth exploring in the future, especially for low-income and middle-income countries, many of whom mainly received TB treatment fund from international donors. ${ }^{54}$ As funding programmes came to an end successively, the scale-up of DR-TB programmes in these countries may be impacted. ${ }^{54}$ Apart from material support, other social support interventions would be indispensable to promote social protection for DR-TB patients. The benefits of emotional, $^{55} 56$ informational $^{57-59}$ and companionship support ${ }^{60-62}$ were widely reported in the patient management of diabetes, hypertension and HIV.

There are still some limitations in this systematic review. First, there was no RCT that met the inclusion criteria. Therefore, there is insufficient evidence to recommend the widespread integration of social support into DR-TB control framework. We call for adequately powered, goodquality, RCTs to evaluate the potential of social support for DR-TB patients. Second, in meta-analysis, there was only one study in the subgroup that did not apply material support. And there could also be heterogeneity in control group as the implementation of NTP could not be completely same in different countries. Therefore, $I^{2}$ could be bias in this small meta-analysis, ${ }^{63}$ and more welldesigned studies are needed to figure out the relationship between material support and other social support, namely emotional support, informational support and companionship support. Third, no sufficient information available about HIV, DOT and socioeconomic status might also introduce heterogeneity, as these factors may relate to individual demand of social support. Finally, plausible heterogeneity was observed in LTFU meta-analysis, but we retained the study ${ }^{11}$ that caused heterogeneity and did not exclude studies on the basis of heterogeneity only, as this might introduce bias.

We hope this study will provide important information for policy-makers that social support interventions have great potential to be effective methods to improve treatment outcomes for DR-TB patients. Limited material support combined with extra social support seems to be a cost-effective approach to promote treatment outcomes, especially for low-income and middle-income countries.

Contributors JY and QS conceptualised the research, provided guidance for SW to develop the protocol. JY and SW conducted the literature search, assessed potentially relevant studies for inclusion into the review, assessed the methodological quality of the included studies, independently extracted the data. SW performed the statistical analysis, drafted the manuscripts and wrote the final manuscript with the assistance of QS and JY. JY, QS and SW performed critical revisions of the manuscript. All authors reviewed the final manuscript.

Funding This study was supported by the National Natural Science Foundation of China (grant number: 71804092) and The Fundamental Research Funds of Shandong University (grant ID: 202708)

Competing interests None declared.

Patient and public involvement Patients and/or the public were not involved in the design, or conduct, or reporting or dissemination plans of this research.

Patient consent for publication Not required.

Provenance and peer review Not commissioned; externally peer reviewed.

Data availability statement Data are available upon reasonable request. All data relevant to the study are included in the article or uploaded as supplementary information. All data relevant to the study are included in the article or uploaded as supplementary information and data are available upon reasonable request.

Open access This is an open access article distributed in accordance with the Creative Commons Attribution Non Commercial (CC BY-NC 4.0) license, which permits others to distribute, remix, adapt, build upon this work non-commercially, and license their derivative works on different terms, provided the original work is properly cited, appropriate credit is given, any changes made indicated, and the use is non-commercial. See: http://creativecommons.org/licenses/by-nc/4.0/.

ORCID iD

Shuqin Wen http://orcid.org/0000-0002-9812-9325 


\section{REFERENCES}

1 World Health Organization. Definitions and reporting framework for tuberculosis-2013 revision. 5. Geneva: World Health Organization, 2013.

2 World Health Organization. Global tuberculosis report 20. 18. Geneva: World Health Organization, 2018.

3 Casali N, Nikolayevskyy V, Balabanova Y, et al. Evolution and transmission of drug-resistant tuberculosis in a Russian population. Nat Genet 2014;46:279-86.

4 Lange C, Chesov D, Heyckendorf J, et al. Drug-Resistant tuberculosis: an update on disease burden, diagnosis and treatment. Respirology 2018;23:656-73.

5 Raviglione MC, Smith IM. XDR tuberculosis--implications for global public health. N Engl J Med 2007;356:656-9.

6 Morens DM, Fauci AS. Emerging infectious diseases: threats to human health and global stability. PLoS Pathog 2013;9:e1003467.

7 Shimao T. [Peculiarity of national tuberculosis program, JapanPublic-Private Mix from the Very Beginning, and Provision of X-ray Apparatus in Most General Practitioner's Clinics]. Kekkaku 2016;91:69-74

8 Sachdeva KS, Kumar A, Dewan P, et al. New vision for Revised National Tuberculosis Control Programme (RNTCP): Universal access - "reaching the un-reached". Indian J Med Res 2012;135:690-4.

9 World Health Organization. Implementing the WHO stop TB strategy: a Handbook for national tuberculosis control programmes. Geneva: World Health Organization, 2008.

10 Lienhardt C, Rowley J, Manneh K, et al. Factors affecting time delay to treatment in a tuberculosis control programme in a sub-Saharan African country: the experience of the Gambia. Int J Tuberc Lung Dis 2001;5:233-9.

11 Li R, Ruan Y, Sun Q, et al. Effect of a comprehensive programme to provide universal access to care for sputum-smear-positive multidrug-resistant tuberculosis in China: a before-and-after study. Lancet Glob Health 2015;3:e217-28.

12 Woeld Health Organization. Global tuberculosis report. Geneva: World Health Organization, 2010.

13 Karumbi J, Garner P. Directly observed therapy for treating tuberculosis. Cochrane Database Syst Rev 2015;5:Cd003343.

14 Blas E, Sivasankara Kurup A, World Health Organization. Equity, social determinants and public health programmes. Geneva: World Health Organization, 2010.

15 Thomas BE, Shanmugam P, Malaisamy M, et al. Psycho-socioeconomic issues challenging multidrug resistant tuberculosis patients: a systematic review. PloS One. 2016;11:e0147397.

16 Theron G, Peter J, Zijenah L, et al. Psychological distress and its relationship with non-adherence to TB treatment: a multicentre study. BMC Infect Dis 2015;15:253.

17 Deshmukh RD, Dhande DJ, Sachdeva KS, et al. Patient and provider reported reasons for lost to follow up in MDRTB treatment: a qualitative study from a drug resistant TB centre in India. PLoS One 2015;10:e0135802.

18 Deshmukh RD, Dhande DJ, Sachdeva KS, et al. Social support a key factor adherence to multidrug-resistant treatment. Indian J Tuberc 2018;65:41-7.

19 Yin J, Wang X, Zhou L, et al. The relationship between social support, treatment interruption and treatment outcome in patients with multidrug-resistant tuberculosis in China: a mixed-methods study. Trop Med Int Health 2018;23:668-77.

20 Fitzpatrick C, Floyd K. A systematic review of the cost and cost effectiveness of treatment for multidrug-resistant tuberculosis. Pharmacoeconomics 2012;30:63-80.

21 Kundu D, Katre V, Singh K, et al. Innovative social protection mechanism for alleviating catastrophic expenses on multidrugresistant tuberculosis patients in Chhattisgarh, India. WHO South East Asia J Public Health 2015;4:69-77.

22 Hutchison C, Khan MS, Yoong J, et al. Financial barriers and coping strategies: a qualitative study of accessing multidrug-resistant tuberculosis and tuberculosis care in Yunnan, China. BMC Public Health 2017;17:221.

23 Weaver MS, Lönnroth K, Howard SC, et al. Interventions to improve adherence to treatment for paediatric tuberculosis in low- and middle-income countries: a systematic review and meta-analysis. Bull World Health Organ 2015;93:700-11.

24 Toczek A, Cox H, du Cros $\mathrm{P}$, et al. Strategies for reducing treatment default in drug-resistant tuberculosis: systematic review and metaanalysis. Int J Tuberc Lung Dis 2013;17:299-307.

25 van Hoorn R, Jaramillo E, Collins D, et al. The Effects of psychoemotional and socio-economic support for tuberculosis patients on treatment adherence and treatment outcomes - a systematic review and meta-analysis. PLoS One 2016;11:e0154095.
26 World Health Organization. Companion handbook to the WHO guidelines for the programmatic management of drug-resistant tuberculosis. Geneva: World Health Organization, 2014.

27 Moher D, Shamseer L, Clarke M, et al. Preferred reporting items for systematic review and meta-analysis protocols (PRISMA-P) 2015 statement. Syst Rev 2015;4:1.

28 van Hoorn R, Jaramillo E, Collins D, et al. The Effects of PsychoEmotional and Socio-Economic Support for Tuberculosis Patients on Treatment Adherence and Treatment Outcomes - A Systematic Review and Meta-Analysis. PLoS One 2016;11:e0154095.

29 Law S, Daftary A, O'Donnell M, et al. Interventions to improve retention-in-care and treatment adherence among patients with drug-resistant tuberculosis: a systematic review. Eur Respir $J$ 2019;53:01030-2018

30 Yin J, Yuan J, Hu Y, et al. Association between directly observed therapy and treatment outcomes in multidrug-resistant tuberculosis: a systematic review and meta-analysis. PLoS One 2016;11:e0150511.

31 Kibret KT, Moges Y, Memiah P, et al. Treatment outcomes for multidrug-resistant tuberculosis under DOTS-Plus: a systematic review and meta-analysis of published studies. Infect Dis Poverty 2017;6:7.

32 Armijo-Olivo S, Stiles CR, Hagen NA, et al. Assessment of study quality for systematic reviews: a comparison of the cochrane collaboration risk of eias tool and the effective public health practice project quality assessment tool: methodological research. J Eval Clin Pract 2012;18:12-18.

33 Thomas $\mathrm{BH}$, Ciliska $\mathrm{D}$, Dobbins $\mathrm{M}$, et al. A process for systematically reviewing the literature: providing the research evidence for public health nursing interventions. Worldviews Evid Based Nurs 2004:1:176-84.

34 World Health Organization. Trade, foreign policy, diplomacy and health. tuberculosis (TB. Geneva: World Health Organization, 2011.

35 Marks SM, Flood J, Seaworth B, et al. Treatment practices, outcomes, and costs of multidrug-resistant and extensively drugresistant tuberculosis, United States, 2005-2007. Emerg Infect Dis 2014;20:812-21.

36 Richterman A, Steer-Massaro J, Jarolimova J, et al. Cash interventions to improve clinical outcomes for pulmonary tuberculosis: systematic review and meta-analysis. Bull World Health Organ 2018;96:471-83.

37 Lutge EE, Wiysonge CS, Knight SE, et al. Material incentives and enablers in the management of tuberculosis. Cochrane Database Syst Rev 2012;1:CD007952.

38 Luyirika E, Nsobya H, Batamwita R, et al. A home-based approach to managing multi-drug resistant tuberculosis in Uganda: a case report. AIDS Res Ther 2012;9:12

39 Oyieng'o D, Park P, Gardner A, et al. Community-based treatment of multidrug-resistant tuberculosis: early experience and results from Western Kenya. Public Health Action 2012;2:38-42.

40 Taneja N, Chellaiyan VG, Daral S, et al. Home based care as an approach to improve the efficiency of treatment for MDR tuberculosis: a quasi-experimental pilot study. J Clin Diagn Res 2017;11:LC05-8.

41 Baral SC, Aryal Y, Bhattrai R, et al. The importance of providing counselling and financial support to patients receiving treatment for multi-drug resistant TB: mixed method qualitative and pilot intervention studies. BMC Public Health 2014;14:46.

42 Brust JCM, Shah NS, Scott M, et al. Integrated, home-based treatment for MDR- TB and HIV in rural South Africa: an alternate model of care. Int J Tuberc Lung Dis 2012;16:998-1004.

43 Acha J, Sweetland A, Guerra D, et al. Psychosocial support groups for patients with multidrug-resistant tuberculosis: five years of experience. Glob Public Health 2007;2:404-17.

44 Mohr E, Daniels J, Beko B, et al. DOT or SAT for rifampicin-resistant tuberculosis? a non-randomized comparison in a high HIVprevalence setting. PLoS One 2017;12:e0178054.

45 Sripad A, Castedo J, Danford N, et al. Effects of Ecuador's national monetary incentive program on adherence to treatment for drugresistant tuberculosis. Int J Tuberc Lung Dis 2014;18:44-8.

46 Bhatt R, Chopra K, Vashisht R. Impact of integrated psychosocio-economic support on treatment outcome in drug resistant tuberculosis - A retrospective cohort study. Indian J Tuberc 2019;66:105-10.

47 Janmeja AK, Das SK, Bhargava R, et al. Psychotherapy improves compliance with tuberculosis treatment. Respiration 2005;72:375-80.

48 Freitas de Andrade KV, Nery JS, de Souza RA, et al. Effects of social protection on tuberculosis treatment outcomes in low or middleincome and in high-burden countries: systematic review and metaanalysis. Cadernos De Saude Publica 2018;34. 
49 Sagbakken M, Frich JC, Bjune GA, et al. Ethical aspects of directly observed treatment for tuberculosis: a cross-cultural comparison. BMC Med Ethics 2013;14:25.

50 Boccia D, Hargreaves J, Lonnroth K, et al. Cash transfer and microfinance interventions for tuberculosis control: review of the impact evidence and policy implications. The International Journal of tuberculosis and lung disease. Int $J$ Tuberc Lung Dis 2011;15:37-49.

51 Ukwaja KN, Alobu I, Gidado M, et al. Economic support intervention improves tuberculosis treatment outcomes in rural Nigeria. Int $\mathrm{J}$ Tuberc Lung Dis 2017;21:564-70.

52 J Carter D, Daniel R, Torrens AW, et al. The impact of a cash transfer programme on tuberculosis treatment success rate: a quasiexperimental study in Brazil. BMJ Glob Health 2019;4:e001029.

53 Lee CY, Chi MJ, Yang SL, et al. Using financial incentives to improve the care of tuberculosis patients. Am J Manag Care 2015;21:e35-42.

$54 \mathrm{Cox} \mathrm{V}, \mathrm{Cox} \mathrm{H}$, Pai M, et al. Health care gaps in the global burden of drug-resistant tuberculosis. Int J Tuberc Lung Dis 2019;23:125-35.

55 Wang $\mathrm{H}$, Zhou J, Huang L, et al. Effects of nurse-delivered home visits combined with telephone calls on medication adherence and quality of life in HIV-infected heroin users in Hunan of China. $J$ Clin Nurs 2010;19:380-8.

56 Ismail K, Winkley K, Rabe-Hesketh S. Systematic review and meta-analysis of randomised controlled trials of psychological interventions to improve glycaemic control in patients with type 2 diabetes. Lancet 2004;363:1589-97.
57 Ma C, Zhou Y, Zhou Y, et al. Evaluation of the effect of motivational interviewing counselling on hypertension care. Patient Educ Couns 2014;95:231-7.

58 Christie D, Thompson R, Sawtell M, et al. Structured, intensive education maximising engagement, motivation and long-term change for children and young people with diabetes: a cluster randomised controlled trial with integral process and economic evaluation - the CASCADE study. Health Technol Assess 2014;18:1-+.

59 Coppola A, Sasso L, Bagnasco A, et al. The role of patient education in the prevention and management of type 2 diabetes: an overview. Endocrine 2016;53:18-27.

60 Willis N, Milanzi A, Mawodzeke M, et al. Effectiveness of community adolescent treatment supporters (CATS) interventions in improving linkage and retention in care, adherence to ART and psychosocial well-being: a randomised trial among adolescents living with HIV in rural Zimbabwe. BMC Public Health 2019;19:117.

61 Bateganya $\mathrm{MH}$, Amanyeiwe $\mathrm{U}$, Roxo U, et al. Impact of support groups for people living with HIV on clinical outcomes: a systematic review of the literature. J Acquir Immune Defic Syndr 2015;68:S368-74.

62 Funck-Brentano I, Dalban C, Veber F, et al. Evaluation of a peer support group therapy for HIV-infected adolescents. Aids 2005;19:1501-8

63 von Hippel PT. The heterogeneity statistic I(2) can be biased in small meta-analyses. BMC Med Res Methodol 2015;15:35. 